\title{
Endothelin 1 gene variant rs5370 and risk of coronary artery disease in the local population of Pakistan, a case-control study
}

Syed Kashif Nawaz ${ }^{1,2}$, Memoona Yousaf ${ }^{2}$, Asima Rani2 ${ }^{2 *}$, Najma Arshad ${ }^{3}$ and Muhammad Arshad ${ }^{4}$

1. Department of Zoology, University of Mianwali, Mianwali-Pakistan

2. Department of Zoology, University of Sargodha, Sargodha-Pakistan

3. Department of Zoology, University of the Punjab, Lahore-Pakistan

4. University of Education, Lower Mall Campus, Lahore-Pakistan

*Corresponding author's email: primer.snp@gmail.com

Citation

Syed Kashif Nawaz, Memoona Yousaf, Asima Rani, Najma Arshad and Muhammad Arshad. Endothelin 1 gene variant rs5370 and risk of coronary artery disease in the local population of Pakistan, a case-control study. Pure and Applied Biology. Vol. 10, Issue 4, pp1427-1435. http://dx.doi.org/10.19045/bspab.2021.100148

\begin{tabular}{llll}
\hline \hline Received: 05/12/2020 & Revised: 19/02/2021 & Accepted: 25/02/2021 & Online First: 22/04/2021 \\
\hline \hline
\end{tabular}

\section{Abstract}

Endothelin 1 is a potent vasoconstrictor peptide. Variation in its gene may modulate the chances of developing coronary artery disease. The present study investigated the role of endothelin 1 genetic variant rs5370 in association with the risk of coronary artery disease in the local population of Pakistan. Study consisted of 318 individuals, out of which 178 were coronary artery disease patients and 140 were normal healthy individuals. Allele specific PCR based strategy was used for the detection of different genotypes of rs5370 polymorphism. $\mathrm{T}$ allele frequency was high in coronary artery disease patients as compared to $\mathrm{G}$ allele frequency. A strong association was observed between this polymorphism and coronary artery disease (chi square=76.34, $\mathrm{p}<0.001$ ). GG genotype showed the protective effects (OR: 0.146, 95\% CI: 0.088-0.240). Discordantly, TT genotype increased 8.818 times the risk of coronary artery disease (OR: 8.818, 95\% CI 5.20714.933). No significant association was noticed between GT genotype and coronary artery disease (OR: 0.644 95\% CI 0.318-1.306). The present findings suggest the important role of rs5370 in modulating the chances of coronary artery disease. TT genotype was found as a risk factor for coronary artery disease in the local population of Pakistan.

Keywords: Coronary artery disease; Endothelin-1; Pakistan; rs5370; Single nucleotide polymorphism

\section{Introduction}

Coronary artery disease (CAD) is the leading cause of human deaths over the globe [1]. It is a complex multifactorial disease. Both genetic and environmental factors contribute in its development and progression [2]. Its most common risk factors include smoking habit, diabetes, hypertension, hypercholesterolemia, obesity, stress, sedentary lifestyle and a family history of heart diseases (genetic factors). Usually there are no signs of disease for a long time. Its 
symptoms start with the chronic vasoconstriction of coronary arteries. As the disease progresses, the lumen of coronary artery can be completely blocked. The restriction in the flow of blood towards heart tissues ultimately leads to heart attack and depending on severity, it may result the sudden death [3].

Endothelin 1 (ET-1) released from the endothelial cells has an important role in maintaining vascular homeostasis. It is a potent vasoconstrictor. It increases the formation of reactive oxygen species and lowers the bioavailability of nitric oxide in vascular endothelium. ET-1 is not only a prominent mediator of vascular tone but also an inflammatory agent for cardiac diseases. It is involved in the activation of transcription factor, nuclear factor kappa $\mathrm{B}(\mathrm{NF}-\kappa \mathrm{B})$ which up regulates the release of pro-inflammatory cytokines. The development of atherosclerotic plaque happens via vascular smooth muscle cell mediated vasoconstriction (VSMC) [4]. Accumulation of VSMC in vascular walls is considered as a hallmark for atherosclerosis [5]. Variations in the level of ET-1 contribute to cardiovascular problems including coronary vasospasm, unstable angina, atherosclerosis, acute and chronic heart failure [6-10].

Association of various polymorphisms in candidate genes with the susceptibility of CAD has been established in the past few years [11, 12, 13]. This highlights the importance of human genetic variations in the pathogenesis of CAD along the traditional risk factors. Gene for ET-1, END1 gene is located at chromosome 6p24.1. Various non-synonymous polymorphisms in END1 gene can modify its activity. A missense single nucleotide polymorphism rs5370 (K198N) in exon 5 of EDN1 gene involves the substitution of guanine $(\mathrm{G})$ nucleotide with thymine (T). This single nucleotide variation causes an amino acid substitution of lysine to asparagine at position 198. It produces ET-1 with different biological activity. $T$ allele of rs5370 polymorphism was found in association with high levels of ET-1, increased chances of hypertension and heart failure [14]. The association studies have indicated that the effect of genotype on the phenotype is different in the different populations. Considering the importance of EDN1 variant rs5370, we designed a case-control study to investigate the role of EDN1 gene variant rs5370 in changing the risk value of CAD in local population of Pakistan.

\section{Materials and Methods}

All procedures of this study followed the declaration of Helsinki. Board of Advance Studies and Research, University of Sargodha, Sargodha, Pakistan permitted the research procedures. Ethical Committee, University of Sargodha permitted the study.

\section{Sample collection}

This study involves 318 human blood samples. Blood samples of local population of Sargodha, Punjab, Pakistan were selected for the study. Samples were collected after proper consent. Three ml venous blood was collected in EDTA coated vials and kept at $20^{\circ} \mathrm{C}$ till future processing. Data for diabetes, hypertension and smoking history was also collected for each sample via sources in hospital. Samples were categorized as diabetic patients based on fasting blood sugar level of $126 \mathrm{mg} / \mathrm{dl}$ or more. Samples were designated as hypertensive individuals based on blood pressure value of more than 140/90 mm Hg. Samples were considered as smokers on the basis of smoking habit of more than five years.

The samples were divided into two groups, CAD group and normal group.

\section{Criteria for CAD group}

The CAD group comprises of 178 angiographically confirmed CAD patients.

\section{Criteria for normal group}

The normal group comprises of 140 healthy volunteers. Healthy volunteers without sign 
and history of any heart problem were enrolled in this group.

CAD group and normal group were matched by age and sex.

\section{Genotyping of rs5370}

From whole blood, genomic DNA was isolated via DNA extraction kit (Cat\# GFBD-100, Vivantis). Two forward primers (Forward 1/F1 and Forward 2/F2) and a reverse primer $(\mathrm{R})$ were designed to amplify rs5370 polymorphism via allele specific PCR strategy. Designed primers were synthesized from Invitrogin, USA through local representatives. F1 primer (F1: 5'ATCCCAAGCTGAAAGGCAAG3') was used for $\mathrm{G}$ allele detection. $\mathrm{F} 2$ primer (F2: 5 ' ATCCCAAGCTGAAAGGCAAT 3') was used for the $\mathrm{T}$ allele detection. The reverse primer (R: 5'TTCTGCTGAG AGGTCCATTG3') was common for both reactions. Reaction mixture of 50ul was prepared using master mix (Invitrogen, Cat. No. 12532-016) and PCR reaction was run in thermocycler. Annealing temperature of primers was $64^{\circ} \mathrm{C}$. For the analysis of PCR product agarose gel of $2 \%$ was used. PCR product size of $321 \mathrm{bp}$ was detected in comparison with DNA marker (Cat. No. 10416-014, Invitrogen), run in the agarose gel.

\section{Statistical analysis}

CAD and normal groups were compared by Student $\mathrm{T}$ test. Estimation of Hardy Weinberg equilibrium (HWE), allele frequencies, gene frequencies and difference in allele and genotype frequencies were analyzed using chi square. SPSS $®$ Software version 18 for windows (SPSS Inc., Chicago Illinois, USA 1989-2003) was used for statistical analysis. Association between various genotypes of rs5370 gene polymorphism and CAD was estimated via odds ratio considering normal group as reference. Effect of risk factors on CAD occurrence was also estimated via odds ratio considering normal group as reference. For the estimation of odds ratio an online calculator was used [15].

\section{Results}

The (Table 1) depicts the characteristics of CAD and normal groups. Groups were similar in terms of age and gender $(\mathrm{P}>0.05)$. Nevertheless, groups were significantly different based on diabetes $(p<0.05)$, hypertension $\quad(\mathrm{p}<0.001)$ and smoking $(\mathrm{p}<0.001)$.

Out of 318 samples, 314 samples gave results of PCR amplification for genotype identification. The samples which did not give amplification results may involve presence of other nucleotides or experimental error. Frequency of $\mathrm{G}$ allele was found higher in case of normal individuals as compared with $\mathrm{T}$ allele. In case of CAD patients, $\mathrm{T}$ allele frequency was observed higher in comparison to frequency of $\mathrm{G}$ allele. When the same data was analyzed collectively, $T$ allele frequency was found to be higher as compared to $\mathrm{G}$ allele. Allele frequencies in normal individuals were deviant from HWE. Similar results were noticed in CAD patients. Results remained unchanged when the stratification impact of disease presence was removed for the analysis (Table 2).

Strong association was found between rs5370 polymorphism and CAD (chi square $=76.34$, $\mathrm{p}<0.001)$. GG genotype decreased 0.146 times the chances of CAD (OR: $0.146,95 \%$ CI 0.088-0.240). Discordantly, TT genotype increased 8.818 times the chances of CAD (OR: 8.818, 95\% CI 5.207-14.933). No significant association was noticed between GT genotype and CAD (OR: $0.64495 \%$ CI 0.318-1.306). Risk of disease occurrence with GT genotype was at margin (Table 3).

The results after consideration of age, sex, diabetes, smoking and hypertension as covariates indicated that $\mathrm{GG}$ allele enhanced 1.007 times the chances of CAD. Heterozygous allele GT and homozygous TT genotypes also increased the chances of CAD but the difference of effects of these 
genotypes was almost same as that of GG. It suggests that rs5370 have minor effects on the onset of CAD (Table 4).

Smoking depicted positive association with CAD ( $p<0.001)$. Smokers have 2.891 times enhanced risk of CAD development as compared with non-smokers (OR: 2.891, CI: 1.809-4.619). Smoking also shows positive association with CAD, when the data was adjusted for age and sex $(\mathrm{p}<0.001)$. It can increase the risk of CAD by 2.841 times (2.841 (1.747 -4.622). Association between diabetes and CAD was observed $(\mathrm{p}<0.05)$, however, the impact of diabetes on the occurrence of CAD was found at margin (OR: 1.602, CI: 0.999-2.567). No significant association was observed between diabetes and CAD after the adjustment of data for age and gender $(p>0.05)$. Significant positive association was observed between hypertension and CAD $(\mathrm{p}<0.001)$. Hypertensive persons have 3.355 times increased chances of developing CAD in comparison to normotensive individuals (OR: 3.355, CI: 2.093-5.378). Hypertension remained a risk factor for $\mathrm{CAD}$ when the data was adjusted for age and sex (OR: 6.749, CI: 3.898- 1.686, $\mathrm{p}<0.001$ ) (Table 5).

\section{Discussion}

Vascular dysfunction may lead towards atherosclerosis, which ultimately proceed towards the development of cardiovascular diseases. ET-1 is a proinflammatory peptide and well known for its role in pathogenicity of vascular endothelium. Its increased production in vascular endothelium aids in the development of atherosclerosis [16]. Its injection in rhesus monkey caused the transient ischemic attack [17].

Polymorphisms in EDN1 gene may alter the production/function of ET-1. rs5370 polymorphism of EDN1 gene has been studied in association with different diseases, originated from vascular dysfunction. The current research investigated the possible association of rs5370 variant of EDN1 gene with CAD in the population of Pakistan. We observed association of rs5370 polymorphism with CAD. T allele was more frequent in CAD patients. TT genotype carriers were found susceptible to $\mathrm{CAD}$ as compared with GG genotype carriers. These results are in consistence with other studies on association of this SNP with cardiovascular diseases.TT genotype was observed as a risk factor for heart failure in Italian Caucasians [18]. It is considered as a risk factor of ischemic stroke in Chinese Han, Japanese and Caucasians [19-21]. This genotype is also considered as risk factor of ischemic stroke and large artery stroke in Ukrainian population [21]. Discordant findings were also reported, as this SNP was not found to be associated with ischemic stroke in Asians [22]. No association between this SNP and ischemic cerebrovascular disease was observed in Turkish population [23].

rs5370 polymorphism was found to be associated with various risk factors for cardiovascular diseases. $\mathrm{T}$ allele was found associated with the susceptibility of hypertension in American population [24]. TT genotype is observed as a risk factor for obesity in Javanese [25] and Japanese population [26]. TT genotype carriers of rs5370 variant are observed as a risk factor of diabetes in Chinese population [27]. TT genotype is reported as a risk factor for obstructive sleep apnea in Caucasians [28]. However, this SNP didn't depict any association with intraventricular hemorrhage in preterm infants of Caucasian population [29]. No association was observed between this SNP and hypertension in Chinese population [30]. This SNP didn't depict association with aneurysm in non-Hispanic Whites [31]. 
Table 1. Characteristics of CAD and normal group

\begin{tabular}{|c|c|c|c|c|}
\hline Characteristics & $\begin{array}{c}\text { CAD } \\
(\mathbf{N = 1 7 8})\end{array}$ & $\begin{array}{c}\text { Normal } \\
(\mathbf{N = 1 4 0})\end{array}$ & $\begin{array}{c}\text { Total } \\
(\mathbf{N = 3 1 8})\end{array}$ & p-value \\
\hline Age (Years) ${ }^{\mathrm{a}}$ & $54 \pm 8.28$ & $52 \pm 17.25$ & $53 \pm 12.8$ & 0.174 \\
\hline Gender Male (\%age) $^{\mathrm{b}}$ & $121(67.97 \%)$ & $97(69.28 \%)$ & $217(68.23 \%)$ & 0.803 \\
\hline Smokers Yes (\%age) $^{\mathrm{b}}$ & $97(54.49 \%)$ & $41(29.28 \%)$ & $138(43.39 \%)$ & $<0.001$ \\
\hline Diabetic Yes (\%age) $^{\mathrm{b}}$ & $71(39.88 \%)$ & $41(29.28 \%)$ & $118(37.10 \%)$ & 0.049 \\
\hline Hypertensive Yes (\%age) $^{\mathrm{b}}$ & $102(57.30 \%)$ & $40(28.57 \%)$ & $142(44.65 \%)$ & $<0.001$ \\
\hline
\end{tabular}

$\mathrm{CAD}=$ coronary artery disease patients involved as cases for study, Normal=healthy individuals involved as controls for study, $\mathrm{p}=$ statistical $\mathrm{p}$-value. aData are shown as mean \pm standard deviation. Students $\mathrm{T}$ test was used for comparison of groups of CAD and Normal. bData are shown as percentage

Table 2. Genotypes and alleles frequencies

\begin{tabular}{|c|c|c|c|}
\hline Genotypes/Alleles & $\begin{array}{c}\text { CAD } \\
(\mathbf{N = 1 7 4})\end{array}$ & $\begin{array}{c}\text { Normal } \\
\mathbf{( N = 1 4 0 )}\end{array}$ & $\begin{array}{c}\text { Total } \\
(\mathbf{N = 3 1 4})\end{array}$ \\
\hline GG & $40(22.98 \%)$ & $94(67.14 \%)$ & $134(37.853 \%)$ \\
\hline TT & $118(67.81 \%)$ & $27(19.28 \%)$ & $145(40.960 \%)$ \\
\hline GT & $16(9.195 \%)$ & $19(13.57 \%)$ & $35(9.887 \%)$ \\
\hline G & 0.28 & 0.74 & 0.48 \\
\hline T & 0.72 & 0.26 & 0.52 \\
\hline HWE (p) & $103.1(<0.001)$ & $58.78(<0.001)$ & $189.4(<0.001)$ \\
\hline
\end{tabular}

HWE=hardy Weinberg Equilibrium, $\mathrm{p}=$ statistical p-value, CAD =coronary artery disease patients involved as cases for study, Normal=healthy individuals involved as controls for study

Table 3. Association between rs5370 gene polymorphism and CAD

\begin{tabular}{|c|c|c|c|}
\hline Genotypes & GG (N= 134) & TT (N=145) & GT (N= 35) \\
\hline CAD (N=174) & 40 & 118 & 16 \\
\hline Normal (N=140) & 94 & 27 & 19 \\
\hline OR & 0.146 & 8.818 & 0.644 \\
\hline (95\% CI) & $(0.088-0.240)$ & $(5.207-14.933)$ & $(0.318-1.306)$ \\
\hline Chi square (p-value) & \multicolumn{3}{|c}{} \\
\hline
\end{tabular}

$\mathrm{OR}=$ odds ratio, $\mathrm{CI}=$ confidence interval, $\mathrm{p}=$ statistical $\mathrm{p}$-value, $\mathrm{CAD}=$ coronary artery disease patients involved as cases for study, Normal=healthy individuals involved as controls for study

Table 4. Effects of genotype on CAD occurrence considering confounding variables (age, sex, diabetes, smoking and hypertension)

\begin{tabular}{|c|c|c|}
\hline Genotypes & p-value & OR (95\% CI) \\
\hline$[\mathbf{G G}] *$ AGE * SEX * DIABETES * SMOKING * \\
HYPERTENSION & $<0.001$ & $1.007(1.005-1.009)$ \\
\hline $\begin{array}{c}\text { HGT] * AGE * SEX * DIABETES * SMOKING * } \\
\text { HYPERTENSION }\end{array}$ & 0.006 & $1.002(1.001-1.003)$ \\
\hline $\begin{array}{c}\text { STT] * AGE * DIABETES * SMOKING * } \\
\text { HYPERTENSION }\end{array}$ & $<0.001$ & $1.004(1.002-1.005)$ \\
\hline
\end{tabular}

$\mathrm{OR}=$ odds ratio, $\mathrm{CI}=$ confidence interval, $\mathrm{p}=$ statistical $\mathrm{p}$-value 
Nawaz et al.

Table 5. Effect of risk factors on CAD occurrence

\begin{tabular}{|c|c|c|c|c|c|c|c|c|c|}
\hline \multirow{2}{*}{\multicolumn{2}{|c|}{ Factors }} & \multicolumn{4}{|c|}{ Analysis without adjustment of data for age and gender } & \multicolumn{4}{|c|}{ Analysis with adjustment of data for age and gender } \\
\hline & & $\begin{array}{c}\begin{array}{c}\text { CAD } \\
(\mathrm{N}=178)\end{array} \\
97\end{array}$ & $\begin{array}{c}\begin{array}{c}\text { Normal } \\
(\mathrm{N}=140)\end{array} \\
41\end{array}$ & \multirow{2}{*}{$\begin{array}{c}\text { OR } \\
(95 \% \mathrm{CI}) \\
2.891 \\
(1.809-4.619)\end{array}$} & \multirow{2}{*}{$\begin{array}{c}\begin{array}{c}\text { Chi square } \\
\text { (p-value) }\end{array} \\
\begin{array}{c}20.27 \\
(<0.001)\end{array}\end{array}$} & \multirow{2}{*}{$\begin{array}{c}\begin{array}{c}\mathrm{CAD} \\
(\mathrm{N}=160)\end{array} \\
87 \\
73\end{array}$} & \multirow{2}{*}{$\begin{array}{c}\begin{array}{c}\text { Normal } \\
(\mathrm{N}=132)\end{array} \\
39 \\
93\end{array}$} & \multirow{2}{*}{$\begin{array}{c}\text { OR } \\
(95 \% \mathrm{CI}) \\
2.841 \\
(1.747-4.622)\end{array}$} & \multirow{2}{*}{$\begin{array}{c}\begin{array}{c}\text { Chi square } \\
\text { (p-value) }\end{array} \\
\begin{array}{c}18.17 \\
(<0.001)\end{array}\end{array}$} \\
\hline & No & 81 & 99 & & & & & & \\
\hline \multirow[t]{2}{*}{ Diabetes } & Yes & 71 & 41 & \multirow{2}{*}{$\begin{array}{c}1.602 \\
(0.999-2.567)\end{array}$} & \multirow{2}{*}{$\begin{array}{c}3.861 \\
(0.049)\end{array}$} & 63 & 39 & \multirow{2}{*}{$\begin{array}{c}1.548 \\
(0.948-2.528)\end{array}$} & \multirow{2}{*}{$\begin{array}{c}3.075 \\
(0.079) \\
\end{array}$} \\
\hline & No & 107 & 99 & & & 97 & 93 & & \\
\hline Hypertension & Yes & 102 & 40 & $\begin{array}{c}3.355 \\
(2.093-5.378)\end{array}$ & $\begin{array}{c}26.17 \\
(<0.001)\end{array}$ & 94 & 23 & $\begin{array}{c}6.749 \\
(3.898-1.686)\end{array}$ & $\begin{array}{c}51.43 \\
(<0.001)\end{array}$ \\
\hline
\end{tabular}

$\mathrm{CAD}=$ coronary artery disease patients involved as cases for study, Normal=healthy individuals involved as controls for study, OR=odds ratio, $\mathrm{CI}=$ confidence interval, $\mathrm{p}=$ statistical $\mathrm{p}$-value 
Association of rs5370 polymorphism with diseases in Asians highlight the importance of this SNP as an important risk factor for Asian ethnicity. This SNP is found as a risk factor for ischemic stroke [Chinese Han population \& Japanese population], obesity [Javanese population and Japanese population and diabetes [Chinese population] [19, 20, 25-27]. Present findings observed the association of this SNP with CAD in Pakistani population. However, Nepal et al. [22] didn't observe this SNP a risk factor for ischemic stroke in Asians. Future studies in various ethnic subgroups of Asians may help to clarify the reasons of the discordant findings.

This is the first study which analyzed the role of rs5370 polymorphism with CAD in the Pakistani population. The enhanced plasma level of ET-1 was observed in the presence of $\mathrm{T}$ allele by some researchers [18, 32]. Nevertheless, the discordant findings were also recorded showing no difference in the plasma levels of ET-1 in the presence of T or $\mathrm{G}$ alleles [33]. The limitations of the current study include the small sample size. Future studies involving large sample size from different ethnic populations and in-vitro analysis of EDN1 levels in different genotypes may validate the results.

\section{Conclusion}

Frequencies of GG, GT and TT were different in CAD patients and normal subjects. rs5370 polymorphism plays important role in mediating the development of CAD. GG genotype shows its protective effects against CAD. Discordantly, the TT genotype enhanced the chances of CAD. Further studies following the metanalysis are required to draw a definitive conclusion.

\section{Authors' contributions}

Conceived and designed the experiments: SK Nawaz, M Arshad \& N Arshad, Performed the experiments: SK Nawaz \& M Yousaf, Analyzed the data: SK Nawaz \& A Rani, Contributed materials/ analysis/ tools: SK
Nawaz, M Arshad \& N Arshad, Wrote the paper: SK Nawaz \& A Rani.

\section{Acknowledgement}

We are thankful to Higher Education Commission Pakistan for providing the funds for completion of this research activity. The research work was presented in oral presentation in The $1^{\text {st }}$ International conference on emerging trends in Zoology (8-9 December 2017) held at University of Sargodha, Sargodha, Pakistan. It was also presented in oral presentation in International conference on Microbiology and Molecular Genetics 2018 (7-9 February 2018) held at University of the Punjab Lahore Pakistan. Its abstract was published in abstract books of these conferences.

\section{Conflicts of interest}

The authors declare no conflicts of interest.

\section{References}

1. WHO (2019). Retrieved From: https://www.who.int/en/newsroom/fact-sheets/detail/cardiovasculardiseases-(cvds).

2. Peden JF \& Farrall M (2011). Thirty-five common variants for coronary artery disease: the fruits of much collaborative labour. Hum Mol Genet 20(R2): R198205.

3. Mcpherson $\mathrm{R}$ \& Tybjaerg-Hansen $\mathrm{A}$ (2016). Genetics of coronary artery disease. Circ Res 118: 564-578.

4. Ramzy D, Rao V, Tumiati LC, Xu N, Sheshgiri R, Miriuka S, Delgado DH \& Ross HJ (2006). Elevated endothelin-1 levels impair nitric oxide homeostasis through a PKC-dependent pathway. Circulation 114(1-Supp): I319.

5. Alexander MR \& Owens GK (2012). Epigenetic control of smooth muscle cell differentiation and phenotypic switching in vascular development and disease. Annu Rev Physiol Ann Rev of Physiol 74: 13-40. 
6. Houde M, Desbiens L \& D'OrléansJuste P (2016). Endothelin-1: biosynthesis, signaling and vasoreactivity. In Adv in Pharmacol, Acad Press 77: 143-175.

7. Caroselli C, De Rosa R, Tanzi P, Rigatelli A \& Bruno G (2016). Endothelial immunomediated reactivity in acute cardiac ischaemia: Role of endothelin 1, interleukin 8 and NTproBNP in patients affected by unstable angina pectoris. Inter J Immunopathol Pharmacol 29(3): 516-522.

8. Lin YJ, Juan CC, Kwok CF, Hsu YP, Shih KC, Chen CC \& Ho LT (2015). Endothelin-1 exacerbates development of hypertension and atherosclerosis in modest insulin resistant syndrome. Biochem Biophys Res Commun 460(3): 497-503.

9. Perez AL, Grodin JL, Wu Y, Hernandez AF, Butler J, Metra M, Felker GM, Voors AA, McMurray JJ, Armstrong PW \& Starling RC (2016). Increased mortality with elevated plasma endothelin-1 in acute heart failure: an ASCEND-HF biomarker substudy. Eur J Heart Fail 18(3): 290-297.

10. Jankowich MD, Wu WC \& Choudhary $G$ (2016). Association of elevated plasma endothelin-1 levels with pulmonary hypertension, mortality, and heart failure in African American individuals: The Jackson Heart Study JAMA Cardiol 1(4): 461-469.

11. Kessler T, Wobst J, Wolf B, Eckhold J, Vilne B, Hollstein R, von Ameln S, Dang TA, Sager HB, Moritz Rumpf P \& Aherrahrou R (2017). Functional Characterization of the GUCY1A3 Coronary Artery Disease Risk Locus. Circulation 136(5): 476-489.

12. Willcox BJ, Morris BJ, Tranah GJ, Chen R, Masaki KH, He Q, Willcox DC, Allsopp RC, Moisyadi S, Gerschenson M \& Davy PM (2017). Longevity- associated FOXO3 genotype and its impact on coronary artery disease mortality in Japanese, Whites, and Blacks: a prospective study of three American populations. J Gerontol A Biol Sci 72(5): 724-728.

13. Turner AW, Martinuk A, Silva A, Lau P, Nikpay M, Eriksson P, Folkersen L, Perisic L, Hedin U, Soubeyrand S \& McPherson R (2016). Functional analysis of a novel genome-wide association study signal in SMAD3 that confers protection from coronary artery disease. Arterioscler Thromb Vasc Biol 36(5): 972-983.

14. Colombo MG, Ciofini E, Paradossi U, Bevilacqua S \& Biagini A (2006). ET-1 Lys198Asn and ETA Receptor H323H Polymorphisms in Heart Failure. Cardiol 105(4): 246-52.

15. Bland JM \& Altman DG (2000). Statistics notes: the odds ratio. Bmj 320: 8.

16. Widmer RJ \& Lerman A (2014). Endothelial dysfunction and cardiovascular disease. Glob Cardiol Sci Pract 3: 43.

17. Dai P, Huang H, Zhang L, He J, Zhao X, Yang F, Zhao N, Yang J, Ge L, Lin Y \& Yu H (2017). A pilot study on transient ischemic stroke induced with endothelin- 1 in the rhesus monkeys. Sci Rep 7: 5097.

18. Colombo MG, Ciofini E, Paradossi U, Bevilacqua S \& Biagini A (2006). ET-1 Lys 198Asn and ETA Receptor H323H Polymorphisms in Heart Failure. Cardiol 105(4): 246-52.

19. Zhang L \& Sui R (2014). Effect of SNP polymorphisms of EDN1, EDNRA, and EDNRB gene on ischemic stroke. Cell Biochem Biophys 70: 233-9.

20. Yamaguchi S, Yamada Y, Metoki N, Yoshida H, Satoh K, Ichihara S, Kato K, Kameyama T, Yokoi K, Matsuo H \& Segawa T (2006). Genetic risk for 
atherothrombotic cerebral infarction in individuals stratified by sex or conventional risk factors for atherosclerosis. Int J Mol Med 8(5): 871883.

21. Dubovyk YI, Oleshko TB, Harbuzova VY \& Ataman AV (2018). Positive Association between EDN1 rs5370 (Lys198Asn) Polymorphism and Large Artery Stroke in a Ukrainian Population. Dis Markers.

22. Nepal G, Ojha R, Dulal HP \& Yadav BK (2019). Association between Lys198Asn polymorphism of endothelin-1 gene and ischemic stroke: A metaanalysis. Brain Behav 9(10): e01424.

23. Aslan O, Gurger M, Atescelik M \& Kara M (2017). Endothelin-1 Lys198Asn and rs10478694 polymorphism in ischemic stroke. Biomed Res 28(2): 750-754.

24. Treiber FA, Barbeau P, Harshfield G, Kang HS, Pollock DM, Pollock JS \& Snieder H (2003). Endothelin-1 gene LYS198ASN polymorphism and blood pressure reactivity. Hypertens 42(4): 494-499.

25. Karita D \& Sadewa AHHP (2019). Association between polymorphism of lys198asn endothelin-1 gene and endothelin-1 plasma level in javanese obesity population. BJMS 18(1):46-49.

26. Jin JJ, Nakura J, Wu Z, Yamamoto M, Abe M, Tabara Y, Yamamoto Y, Igase M, Kohara K \& Miki T (2003). Association of endothelin-1 gene variant with hypertension. Hypertens 41(1): 163-167.

27. Li H, Louey JW, Choy KW, Liu DT, Chan WM, Chan YM, Fung NS, Fan BJ, Baum L, Chan JC \& Lam DS (2008). EDN1 Lys198Asn is associated with diabetic retinopathy in type 2 diabetes. Mol Vis 14: 1698-1704.
28. Diefenbach K, Kretschmer K, Bauer S, Malzahn U, Penzel T, Roots I \& Fietze I (2009). Endothelin-1 gene variant Lys 198Asn and plasma endothelin level in obstructive sleep apnea. Cardiol 112(1): $62-68$.

29. Szpecht D, Gadzinowski J, SeremakMrozikiewicz A, Kurzawińska G \& Szymankiewicz M (2016). Role of endothelial nitric oxide synthase and endothelin-1 polymorphism genes with the pathogenesis of intraventricular hemorrhage in preterm infants. Sci Rep 7: 1-9.

30. Fang Z, Li M, Ma Z \& Tu G (2017). Association of endothelin-1 gene polymorphisms with essential hypertension in a Chinese population. Genet Mol Res 16(3): 1-7.

31. Gallek M, Alexander S, Crago E, Sherwood P, Horowitz M, Poloyac S \& Conley Y (2013). Endothelin-1 and endothelin receptor gene variants and their association with negative outcomes following aneurysmal subarachnoid hemorrhage. Biol Res Nurs 15(4): 390397.

32. Barden AE, Herbison CE, Beilin LJ, Michael CA, Walters BN \& Van Bockxmeer FM (2001). Association between the endothelin-1 gene Lys198Asn polymorphism blood pressure and plasma endothelin-1 levels in normal and pre-eclamptic pregnancy. J Hypertens 19(10):17751782.

33. Tanaka C, Kamide K, Takiuchi S, Kawano Y \& Miyata T (2004). Evaluation of the Lys198Asn and134delA genetic polymorphisms of the endothelin-1 gene. Hypertens Res 27(5): 367-371. 